\title{
Clínica de un paciente con linfoma no Hodgkin post quimioterapia y radioterapia. Revisión de literatura y caso clínico
}

\section{Post chemotherapy and radiotherapy non-Hodgkin's limphoma patient clinic. Literature review and clinical case}

\author{
Febres-Calderón Fabricio*1, Quito- Vallejo Erica ${ }^{2}$ \\ ${ }^{1}$ Rotante de Investigación en la Universidad Católica de Cuenca, Ecuador. Odontólogo de práctica privada. Loja,Ecuador. \\ ${ }^{2}$ Docente Especialista en Rehabilitación Oral. Universidad Católica de Cuenca. Cuenca, Ecuador. \\ *fafebres@gmail.com
}

\begin{abstract}
Resumen
El objetivo de esta revisión de literatura se enfoca en indicar las características clínicas intraorales de un paciente oncológico diagnosticado con Linfoma No Hodgkin, estableciendo la relación existente con el estado de salud oral y el haber recibido tratamiento de Quimioterapia y Radioterapia, señalando además modificaciones en la estructura dental como el deterioro por erosión del tejido adamantino y dentinario y por consiguiente el colapso de los componentes de estos tejidos que conforman la estructura dental fundamental. Se identificó información que permite correlacionar los signos y síntomas que ha presentado la paciente durante y después del tratamiento, además sugerir el desarrollo de una guía clínica médico-odontológica para ayudar a obtener un mejor estilo de vida y control de los procesos intraorales que se desencadenan durante el período pre y post tratamiento oncológico.
\end{abstract}

Palabras clave: Quimioterapia; Radioterapia; Linfoma No Hodgkin, Erosión dental, Prevención.

The objective of this literature review is focused on indicating the intra-oral clinical characteristics of an oncological patient diagnosed with Non-Hodgkin's Lymphoma, establishing the existing relationship with the state of oral health and having received Chemotherapy and Radiotherapy treatment, also pointing out modifications in the dental structure such as deterioration by erosion of the adamantine and dentine tissue and consequently the collapse of the components of these tissues that make up the fundamental dental structure. Information was identified that allows the correlation of the signs and symptoms that the patient has presented during and after the treatment. In addition, the development of a medical-dental clinical guide is suggested to help obtain a better lifestyle and control of the intraoral processes that are triggered during the pre and post oncological treatment period.

Key words: Chemotherapy; Radiotherapy; Lymphoma Non-Hodgkin; Tooth erosion; Prevention.

\section{INTRODUCCIÓN}

El Linfoma de No Hodgkin es un tipo de cáncer del tejido linfático que empieza alterando su función, es así que se puede localizar en cualquier parte del cuerpo y afecta a dicho sistema el cual ayuda a combatir infecciones a través de una amplia función inmunitaria realizada por los ganglios linfáticos que se conectan por vasos linfáticos y se encuentran distribuidos por todo el cuerpo, en el Bazo que filtra las células sanguíneas dañadas, en Médula ósea donde se producen células sanguíneas y también linfocitos, en el Timo localizado a nivel superior del pecho para el desarrollo de Linfocitos T, Amígdalas y Adenoides, estas se localizan a nivel de cuello posteriores a la garganta. ${ }^{1}$ Las modificaciones a la condición de salud de la cavidad oral de los pacientes oncológicos, se ha reportado desde los años 1900 y 1940 para radioterapia en primera instancia y para quimioterapia como segundo punto, señalando complicaciones orales secundarias como efecto de estos tratamientos antineoplásicos, el difícil acceso a los sistemas de salud confieren dificultad para una atención oportuna odontológica de los pacientes tratados por cáncer, la falta de integración de la atención odontológica a los programas de tratamiento de estos pacientes, también favorecerá a que estas manifestaciones deriven en complicaciones más graves para ser tratadas. ${ }^{28}$ Los signos clínicos orales que se presentan en los pacientes con cáncer y por efecto de su tratamiento de quimioterapia se da con distinción hacia osteorradionecrosis, candidiasis, trismo, xerostomía, procesos de periodontitis agudas, caries por radiación, disfagia, estas aparecerán en distintas etapas de la enfermedad y del tratamiento, por consi- 
guiente uno de los signos clínicos intraorales de importancia es la caries dental que tendrá un efecto cascada, es decir traerá consigo la aparición de distintos procesos patológicos, dolor dental, abscesos de origen odontogénico, llegan en ocasiones a complicarse hacia celulitis y otros tipos de infecciones orofaciales. ${ }^{18} \mathrm{El}$ uso de radioterapia como tratamiento para el cáncer en su lugar de origen o localización, debe venir acompañada de la concepción de Radiación en Dosis recibida y absorbida, actualmente ésta dosis se mide en centi Gray (cGy), dependiendo de la localización se puede utilizar Tele terapia y Braquiterapia. La radiación ionizante puede ir de 30 a 80 cGy en el tumor y 10-50 cGy en el área de los tejidos adyacentes, mayormente se suelen otorgar a $200 \mathrm{cGy}$ a la semana durante 5 días. $^{2}$ El proceso de quimioterapia, sugiere el uso de medicamentos que ataquen a las células cancerígenas durante distintas fases de desarrollo y vida de las mismas, estos medicamentos alquilantes intervienen en las células y destruyendo su $\mathrm{ADN}$, impidiendo su réplica, también comienza a ejercer su efecto sobre células de la médula ósea, ${ }^{3}$ se presentan efectos derivados de la toxicidad por quimioterapia como; cefaleas, vómitos, dolor lumbar, parestesias, lo que puede guiarnos hacia una leve pérdida de sensibilidad y daño pulpar por lo tanto la disminución de sensibilidad dental ante procesos cariosos extensos. ${ }^{4}$ Esta toxicidad nos dirige hacia episodios de bulimia nerviosa, por lo cual estos pacientes tienden a modificar su dieta y la progresiva pérdida de apetito harán que estos modifiquen su comportamiento frente a la alimentación llegando incluso a omitir ciertos momentos de alimentación, llevándolo a un proceso de anorexia asociado a bulimia nerviosa, principalmente establecido por el tratamiento de quimioterapia y radioterapia en diversas localizaciones del tumor, principalmente neoplasias malignas, se estima que entre un 15 y $25 \%$ de los pacientes oncológicos se de este proceso de anorexia que desencadenará en bulimia, alcanzando a complicar el cuadro del paciente. ${ }^{5}$ la modificación en la función de glándulas salivales, otorgará un notable aumento de riesgo de acúmulo de placa bacteriana y llevará a alteraciones en los distintos tejidos orales, la alteración de estos ambientes determina que los pacientes oncológicos tengan un alto riesgo de generación de caries, enfermedad periodontal, pérdida dentaria, palidez de mucosa gingival y gingivitis. ${ }^{6}$ Cuando el flujo salival normal se encuentra entre $0.3 \mathrm{ml} / \mathrm{min}$ llegando hasta $500 \mathrm{ml}$ o $600 \mathrm{ml}$ al día, en un paciente oncológico con se presentará Xerostomía por la modificación en la cantidad del flujo y la composición química de la saliva, desencadenando disminución de las funciones anti cariogénicas, de amortiguación y neutralización de agentes ácidos de la saliva, todo esto sumado a una dieta que tiene un alto contenido de carbohidratos confiere una mayor fermentación de sus residuos y por lo tanto un cambio en el $\mathrm{pH}$ del medio bucal.1 la sensación de ardor, lengua seca y afecta a la población en general entre un 10 y $20 \%$ con mayor predilección por las mujeres y en pacientes oncológicos que han sido tratados con una radiación superior a los $30 \mathrm{cGy}^{7}$ la composición de la saliva con alto contenido de calcio y fosfatos, fundamentales para la remineralización del esmalte le permiten tener capacidad tampón, y ante la alteración de la función glandular podemos observar que se generan lesiones a nivel cervical, de bordes y cúspides cuando la función de las glándulas salivales se ve afectada y el $\mathrm{pH}$ puede llegar hasta 4,5 siendo promotor de la aparición de lesiones de caries al presentar un ambiente adecuado para la proliferación bacteriana y depósito de placa en la superficie dental, ${ }^{8}$ al disminuir la capacidad de remineralización la posibilidad de erosión o corrosión del tejido dental que se ve estructuralmente debilitado por la falta de depósito mineral aumenta. ${ }^{9}$ El contenido inorgánico permite que la formación de una película adquirida del esmalte brinde protección ante fuerzas erosivas y de atrición, inhibe el depósito mineral sobre el esmalte que está compuesto de hidroxiapatita $(\mathrm{Ca}) 10(\mathrm{PO} 4) 6(\mathrm{OH}) 2$, pero se permite la fluidez de iones de calcio y fosfato que pueden pasar a través de estos cristales y permitir la remineralización. ${ }^{10}$ Un esmalte no irradiado presenta prismas bien organizados de forma transversal y oblicua, rodeados por más primas, cuando el esmalte es sometido a choques de radiación acumulativa entre 10, 20 o 30 cGy, se observará disminución en la resistencia de varias porciones de su estructura, si la radiación llega a acumularse hasta 60 cGy en la región inter-prismática se darán cambios micro-morfológicos ligeros, al igual que en la dentina a nivel inter-tubular, peri-tubular e intra-tubular, se puede observar obliteración de túbulos dentinarios y fibras colágenas fragmentadas. ${ }^{11}$ (figura 1 y 2 )
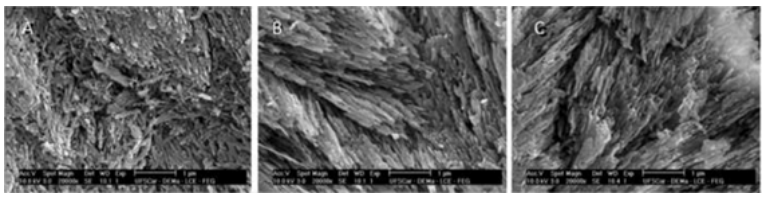

Fig. 1. Vista del esmalte en microscopio de barrido (20000x). A) Esmalte sin exposición a radiación y bien organizado, con su región interprismática establecida. B) Esmalte expuesto a 30 cGy. C) Esmalte expuesto a $60 \mathrm{cGy}$. La región interprismática se irradia y muestra claramente los prismas y cristales. ${ }^{11}$ 

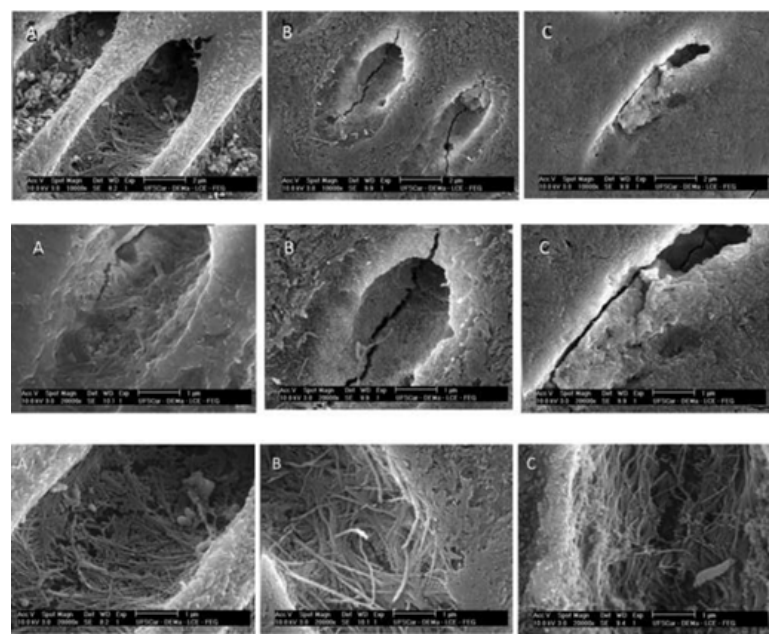

Fig. 2. Vista de dentina en microscopio de barrido (10000x). A) Dentina sin exposición a radiación con buena definición de los túbulos y la red colágena bien organizada. B) Dentina expuesta a 30 cGy. C) Dentina expuesta a 60 cGy, mostrando alteración intertubular y peritubular, además de cracks en la estructura y obliteración de los túbulos dentinarios.(20000x) A) Dentina sin exposición a radiación con buena definición de los túbulos y la red colágena bien organizada. B) Dentina expuesta a 30 cGy. C) Dentina expuesta a $60 \mathrm{cGy}$, mostrando alteración intertubular y peritubular, además de cracks en la estructura y obliteración de los túbulos dentinarios e incremento en la destrucción de fibras colágenas. ${ }^{11}$

Luego de haber sido expuesto el esmalte a radiación, claramente la estructura prismática se observa desordenada, además en dentina la degeneración de la red colágena es obvia, permitiéndose mostrar en la pared tubular grietas, además se compromete la unión amelodentinaria, con la consecuente fractura debido a que la microdureza y módulo elástico pierden su capacidad de resistencia cerca a dicha unión esto por el cambio mineral y proteico existente, la relación calcio-fosfato en el esmalte sano es alta pero en pacientes que han recibido radioterapia, esta relación se desintegra y la apatita pierde calcio favoreciendo la desmineralización. ${ }^{12}$ (figura 3)

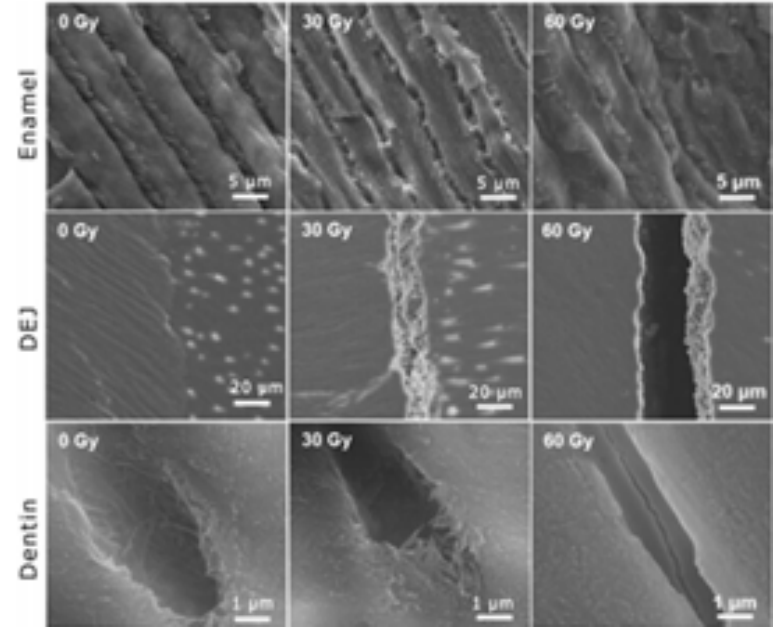

Fig. 3. Vista de microscopio de barrido electrónico, mostrando la exposición de esmalte, dentina y unión amelodentinaria, donde se puede observar la pérdida de sustancia interprismática, a 30 y 60 cGy, se muestran fisuras en la unión amelodentinaria, y obliteración de túbulos dentinarios, además de degeneración de la unión de fibras colágenas y cracks en las paredes de los túbulos dentinarios. ${ }^{12}$

Un cambio estructural en el esmalte es la erosión, que se puede determinar por el colapso de unión entre cristales de hidroxiapatita entre estos encontramos una proteína denominada Amelogenina Hidrofóbica la cual se dispone entre estas, esta proteína es de disolución acídica por cuanto cuando existe una disminución del $\mathrm{pH}$ se puede disolver esta unión donde se rompe el enlace estable para los cristales minerales y se produce una desmineralización ${ }^{13}$ y por consiguiente posible invasión oportunista bacteriana aumentando el riesgo de daño en la estructura por aumento de actividad acídica, favoreciendo la aparición de procesos cariosos, que gracias el avance de estudios sobre su etiopatología se demuestra que se da por un proceso de desmineralización de los componentes de los dientes, siendo el esmalte el principal afectado, todo esto tiene su origen a nivel microscópico, y por actividad de proteinasas que generan degradación de la matriz extracelular, pero regulada por los TIMPs que son inhibidores de metaloproteinasas, función que en diversos procesos patológicos se puede ver alterada e inactivada. ${ }^{14}$ En la formación del esmalte dental también se encuentran estas y a partir de ameloblastos, se dirigen hacia la dentina ya formada, para estructurar una capa de esmalte denominado aprismático, pero el ameloblasto es el encargado de la formación de proteínas que serán secretadas en la matriz de esmalte, una primera la Amelogenina-AMELX en un 80$90 \%$, Ameloblastina - AMBN y Enamelina el 5\% y la Enamelisina o MMP-20. ${ }^{15}$ En diversos estudios sobre Caries se encuentra un alto contenido de esta Metaloproteinasas MMP-2, 8, 9 y 20 pero esta última en mayor concentración, a nivel dentinario en terceros molares, ${ }^{16}$ en pacientes que hayan sido sometidos a radiación se han encontrado cambios 
estructurales específicamente dirigidos de las MMP-20 donde a una exposición de 60 cGy, se tornan resistentes a la radiación y pueden generar la degradación de matriz extracelular y favorecer al colapso de la estructura del esmalte. ${ }^{17}$

\subsection{Manejo de Pacientes Previo Radioterapia y Quimiote- rapia.}

El manejo odontológico del paciente oncológico es importante en los distintos momentos del tratamiento de cáncer, es así que se debe realizar un minucioso chequeo intraoral, para establecer condiciones clínicas orales que puedan ser de consideración durante el tratamiento del paciente, puesto que estas manifestaciones que pueden ser lesiones de caries, mucositis, gingivitis durante el protocolo de radioterapia y quimioterapia pueden complicarse mucho más y resultar en complicaciones futuras para el paciente, estas manifestaciones pueden generar complejidad desde la segunda semana de tratamiento, y el acúmulo de radiación recibida será una detonante.18, es fundamental el manejo médico-odontológico que debe ir desde su diagnóstico y acompañar durante todo el proceso al paciente; la incorporación de especialistas de diversas áreas odontológicas facilitarán el manejo de las diversas manifestaciones clínicas orales, la motivación hacia un manejo adecuado de la higiene ayudará a controlar los cambios que puedan darse y minimizar el riesgo de un daño mayor, establecer protocolos según la importancia clínica y derivados en establecer la complejidad y nivel de riesgo significante para el paciente. ${ }^{18}$

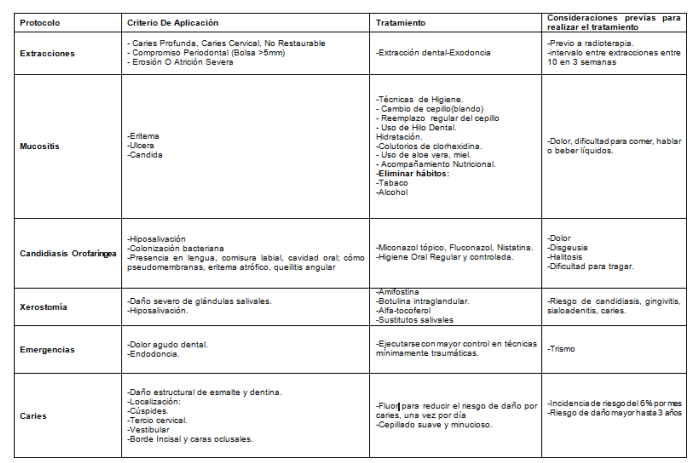

Tabla 1. Consideraciones de atención Odontológica a pacientes Oncológicos. ${ }^{19}$

\section{CASO CLÍNICO}

La aplicación de tratamientos antineoplásicos como quimioterapia y radioterapia, generan daño a nivel estructural y de tejidos del complejo bucal. Se deben considerar múltiples signos que presente el paciente, para ello el examen clínico intraoral, radiográfico y fotográfico ayudarán a mejorar el diagnóstico, el manejo y plan de tratamiento para resolución del problema que presente el paciente, es importante analizar al paciente en el contexto que se presenta y así determinar los principales motivos por los cuales acude a consulta, y establecer la relación entre el daño estructural y la condición de salud general del individuo. Paciente femenino de 30 años de edad, acude a consulta odontológica donde refiere inconformidad con la estética actual de sus dientes, donde se solicitó radiografía panorámica para establecer compromiso de la estructura ósea y dental, la paciente refiere ser tratada por Linfoma de NoHodgkin, para lo cual se profundizó en la entrevista determinando signos y síntomas que se hayan presentado antes, durante y después del tratamiento de quimioterapia y radioterapia, a lo cual señala haber tenido episodios repetitivos de bulimia nerviosa para lo cual ha sido medicada. Se refiere ser tratada por RCHOP del 2013 al 2015, recibiendo también ciclo de radioterapia, ha trabajado con Emend hasta el año 2017 medicamento recetado para control de bulimia nerviosa, y zinc puro hasta el mismo año. Entró en periodo de gestación y suspendieron estos medicamentos para usar solo multivitamínicos, posterior al embarazo se ha medicado antidepresivos, ansiolíticos hasta la actualidad, adicional calcio y multivitamínicos, manteniendo terapéutica para control vómitos involuntarios, permanentemente hierro, y vitamina C desde el 2015, refiere además ya haber sido tratada en ocasiones anteriores en el área odontológica y dichas restauraciones siempre han tenido poco tiempo de vida en boca por lo cual siempre se han desalojado, datos proporcionados por la paciente. Posterior a la entrevista se procede al protocolo fotográfico de registro, obteniendo fotografías en MIC; frontal y laterales; intraorales oclusal superior e inferior. (figura 4)

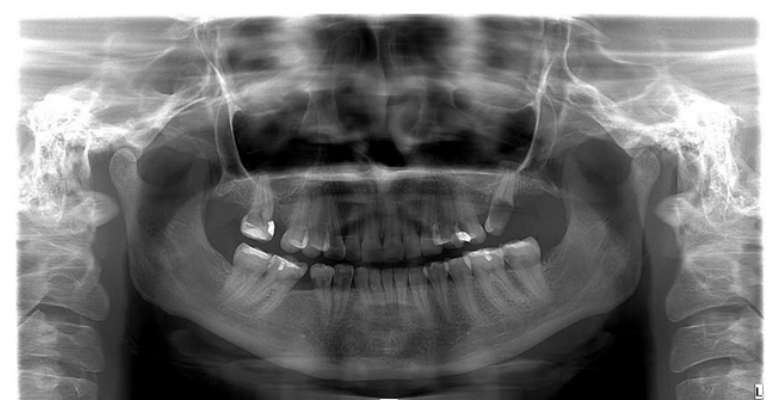

Fig. 4. Radiografía Panorámica. Ausencia de piezas dentales, restauraciones, lesiones cariosas. (previo a exodoncia de pieza 2.7)

Durante el examen clínico intraoral se encontró restauraciones de resina en caras oclusales y ionómero de vidrio en su margen cervical. Además de marcas de pulido horizontal con instrumento rotatorio, erosión a nivel cervical por lesiones cariosas, facetas de desgaste en piezas anteriores y posteriores en bordes incisales y cuspídeos donde se observa cavitación a través de esmalte, y señal de desgaste palatino por erosión ácida en dientes anteriores.(figura 5) 


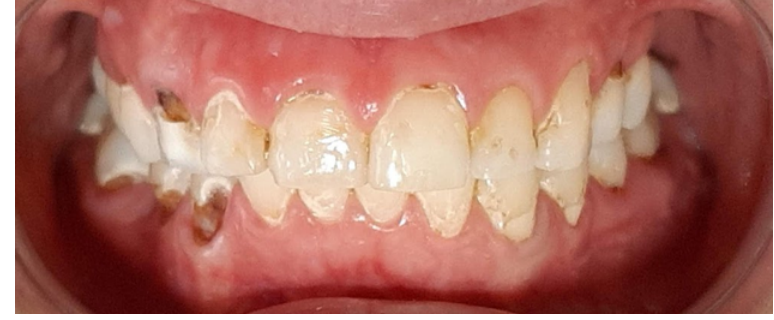

Fig. 5. Fotografía Intraoral Frontal con múltiples lesiones cariosas.
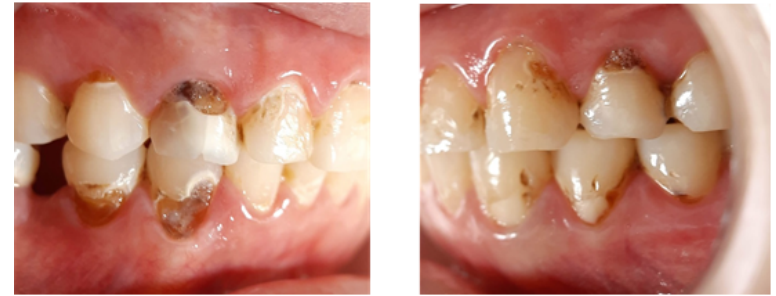

Fig. 6. Fotografía $3 / 4$ intraoral. Lesiones cervicales y estructurales en esmalte y dentina, restauraciones cervicales defectuosas

A nivel del esmalte se puede observar cambios de la estructura en generalidad y líneas de fractura verticales del esmalte, lesiones cervicales y cavitarias en caras vestibulares, líneas de manchas blancas entre lesiones y cavidades cervicales, se puede observar daño estructural de dentina en cervical y pérdida de borde cuspídeo de canino y primer premolar superior e inferior.(figura 6 y 7)

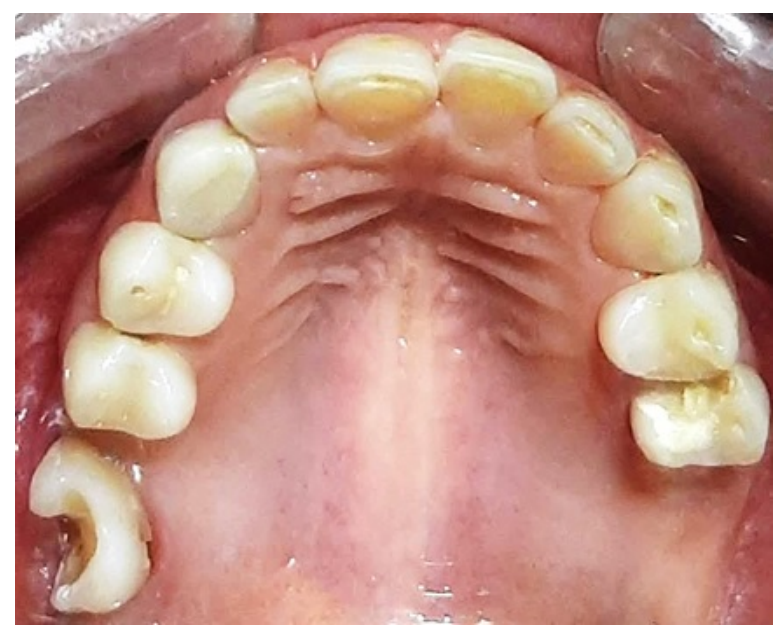

Fig. 7. Vista oclusal superior, ausencia de molares izquierdos, lesiones de caries y desgaste de facetas.

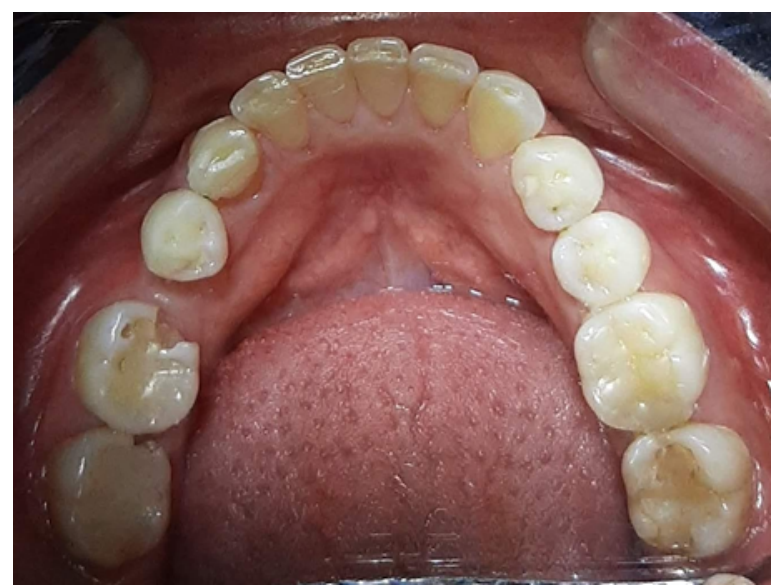

Fig. 8. Vista oclusal inferior, múltiples restauraciones en mal estado.

\section{DISCUSIÓN}

Durante la revisión clínica odontológica de un paciente que ha sido sometido al protocolo de tratamiento oncológico, según la Sociedad Americana del Cáncer describe en 2018, que se debe tomar en cuenta el tipo de cáncer y su estadio, y duración del tratamiento, si este ha sido concluido se encuentra intermitente o se encuentra en fase activa. Determinar localización del foco para el tratamiento con radioterapia, ${ }^{20}$ signos clínicos característicos Intraorales, signos y síntomas generales basados en la anamnesis previa del paciente, donde se podrán determinar factores que puedan llegar a modificar la condición de salud bucal del paciente. Rosten y Newton en su reporte de 2017, señalan que se puede observar destrucción y pérdida de la sustancia adamantina que se extiende en todo su espesor permitiendo la exposición dentinaria por erosión generada por bulimia ${ }^{21}$ y por consiguiente mayor avance de la destrucción de tejido por componentes generadores de caries dental. La condición del esmalte del paciente que ha sido sometido a tratamiento de quimioterapia y radioterapia, se define por los signos clínicos encontrados como, líneas de fractura del esmalte, lesiones cariosas, pérdida de piezas y pérdida de restauraciones con materiales resinosos, por ende la condición del tejido será compleja en cuanto al grado de rehabilitación de sus piezas dentarias dando como finalidad un nivel muy bajo de adhesión de materiales a la estructura dental remanente, como indica Nakajima y colaboradores en 2011, mostrando la condición de la dentina afectada por caries con cambio, morfológico, químicos y físicos que generan disminución en los valores adhesivos generando deterioro de la interfaz adhesiva. $^{22}$ Para el tratamiento de dicho paciente se ha tomado en cuenta el nivel socio-económico, predisposición a realizarse un tratamiento que permita recuperar la función y estética del complejo oral, estado anímico e impacto psicológico de la condición actual, lesiones radiculares en piezas con compromiso de restauraciones complejas y que pueden ser focos infecciosos, para lo cual se ha propuesto 
un protocolo que abarque realizar endodoncias en piezas que tengan compromiso estructural extenso por perdida de sustancia dental y daño de restauraciones directas en mal estado y que radiográficamente muestren signos de lesión periapical y compromiso cameral, y restauraciones indirectas de cerómero para recuperar la estructura comprometida tanto a nivel cervical como de toda la estructura dental deteriorada y restablecer la función y estética, técnica recomendada para su manejo por Besek, ${ }^{23}$ previa remoción de tejido cariado, se debe añadir el protocolo de endodoncia ceñido en el manejo cauteloso de todo el procedimiento descrito por Mora en 2017 indicando cambios micro morfológicos del complejo pulpar desde 1 cGy a la par se presenta disminución de la sensibilidad pulpar a de 30 a 35 cGy de aplicación del tratamiento de radioterapia, para lo cual se deberá derivar tempranamente al examen odontológico y determinar la necesidad de tratamiento endodóntico. ${ }^{24}$ Puede ser una alternativa al tratamiento la aplicación de restauraciones indirectas preformadas para lesiones del esmalte que abarque el tercio cervical, medio e incisal. Inclusive el uso de restauraciones indirectas feldespáticas o disilicato de litio descrito por Vailati en $2008,{ }^{25}$ integrarán un mejor resultado estético, logrando recuperar la zona estética y funcional activa del complejo dental la complejidad en la decisión del tratamiento radica en la condición económica de la paciente. Para la atención odontológica del paciente oncológico actualmente en el Ecuador se han presentado propuestas de protocolos de atención a ser aplicados como tesis de pregrado, a nivel del Ministerio de Salud Pública no se encuentra un protocolo establecido de atención completa del equipo de salud constituido por médicos, odontólogo y personal de enfermería, datos encontrados datan de la última actualización de protocolos odontológicos del ministerio de salud del año 2014, el cual señala específicamente protocolo de atención de Cáncer Oral, ${ }^{26}$ donde se indican manifestaciones clínicas Intraorales como las descritas en el presente reporte, no existe una guía clínica de atención previa, durante y después de un tratamiento oncológico, para la atención integral de dichos pacientes. ${ }^{27}$ Es fundamental recomendar mayor énfasis en el criterio de inclusión del personal odontológico en el diagnóstico y manejo de los pacientes oncológicos, así como incentivar la cátedra al interés de la investigación de signos clínicos presentes, y elaboración de guía de manejo de pacientes con cáncer en el ámbito odontológico desde el inicio de su diagnóstico hasta el final de su tratamiento oncológico.
CONFLICTO DE INTERESES: Los autores no manifiestan ningún conflicto de interés.

\section{Referencias Bibliográficas}

1 ¿Qué es el linfoma no Hodgkin? [Internet]. Cancer.org. 2020 [citado 1 Julio 2020]. Disponible en:https://www.cancer.org/es/cancer/linfoma-

no-hodgkin/acerca/que-es-linfoma-no-

hodgkin.htmlreferencias.

2 Hurtado Redondo DC, Estrada Montoya JH. Manejo odontológico de pacientes sometidos a radioterapia: revisión de literatura. Acta Odontológica Colombiana. 2012; 02(02).

3 Cómo funcionan los medicamentos de quimioterapia [Internet]. Cancer.org. 2020 [citado 29 Junio 2020]. Available from: https://www.cancer.org/es/tratamiento/tratamientosy-efectos-secundarios/tipos-de-

tratamiento/quimioterapia/como-funcionan-los-

medicamentos-de-quimioterapia.html

4 Olmos Jiménez, Díaz Carrasco MS, Cabañas Perianes , Valderrey Pulido, Espuny Miró A. Evaluation of standardized triple intrathecal therapy toxicity in oncohematological adult patients. Farmacia Hospitalaria. 2017; 41(5).

5 Sánchez Lara K, Sosa Sánchez R, Green Renner D, Méndez Sánchez N. Observaciones sobre la patogénesis de la anorexia asociada a cáncer y su regulación por el sistema nervioso central. Nutrición Hospitalaria. 2011; 26(04).

6 Gallego Martínez J. Estado de Salud Bucodental de los Pacientes con Linfoma que van a ser Tratados en la Región de Murcia. Tesis Doctoral. Murcia: Universidad De Murcia, Departamento De Dermatología, Estomatología, Radiología Y Medicina Física; 2016.

7 Chapa AG, Garza SM, Garza EM, Martínez SG. Hiposalivación y xerostomía; diagnóstico, modalidades de tratamiento en la actualidad: Aplicación de neuroelectroestimulación. Revista Mexicana de Peridontología. 2012 Enero - Abril; 3(1).

8 Barrios, Vila, Martinez, Encina Tutuy AJ. Ph Salival como factor asociado a la caries dental. Revista Facultad de Odntología. 2017; 10(1).

9 Holanda Rolim E, João da Costa , Pedreira Ramalho. Impact of radiotherapy on the orofacial region and management of related conditions. Radiología Brasileira. 2011 Noviembre Diciembre; 44(6).

10 Dawes C, L Pedersen AM, Villa A, Ekström J, Protor GB, Vissink A, et al. The functions of human saliva: A review sponsored by the World Workshop on Oral Medicine VI. Archives Of Oral Biology. 2015 Junio; 60(6).

11 Napolitano Gonçalves L, Palma-Dibb , Paula Silva, De Oliveira , Filho N, Bezerra da Silva, et al. Radiation therapy alters microhardness and microstructure of enamel and dentin of permanent human teeth. Journal of dentistry. 2014 Junio; 42(8) 
$12 \mathrm{Lu} \mathrm{H,} \mathrm{Zhao} \mathrm{Q,} \mathrm{Guo} \mathrm{J,} \mathrm{Zeng} \mathrm{B,} \mathrm{Yu} \mathrm{X,} \mathrm{Yu} \mathrm{D,} \mathrm{et} \mathrm{al.} \mathrm{Direct}$ radiation-induced effects on dental hard tissue. Radiation Oncology. 2019 Enero; 14(5).

13 Valencia R, Espinosa R, Ceja I, Marín A. Características 27 estructurales de los Cristales del Esmalte Humano: Mecanismos de Remineralización. Revista de Operatoria Dental y Biomateriales. 2013 Septiembre - Diciembre; 2(3).

14 Díaz Caballero A, Méndez Cuadro D, Martínez Serrano E, Orozco Páez J, Rosa Velásquez M. Metaloproteinasas de la matriz en Odontología y sus consideraciones desde el campo de la química computacional. Revista Cubana de Estomatología. 2014 Enero - Marzo; 51(1).

15 Cuéllar rivas E, Pustovrh Ramos C. El Papel De La Enamelisina (Mmp-20) En El Desarrollo Dentario. Revisión Sistemática. Revista Facultad de Odontología Universidad de Antioquia. 2015 Julio - Diciembre; 27(1).

16 Shimada Y, Ichinose S, Sadr A, Burrow M, Tagami J. Localization of matrix metalloproteinases (MMPs-2, 8, 9 and 20) in normal and carious dentine. Australian Dental Journal. 2009 Diciembre; 54(1).

17 McGuire JD, Mousa AA, Zhang BJ, Todoki LS, Huffman NT, Chandrababu KB, et al. Extracts of irradiated mature human tooth crowns contain MMP-20 protein and activity. Journal of Dentistry. 2014 Marzo; 42(5).

18 Rebolledo Cobos ML, Toloza Gutiérrez P, Alonso Drujes D. Condiciones estomatológicas en pacientes con cáncer durante y posterior al tratamiento antineoplásico: revisión narrativa de la literatura. Revista Nacional de Odontología. 2017 Enero; 13(24).

19 Beech N, Robinson S, Porceddu S, Batstone M. Dental management of patients irradiated for head andneck cancer. Australian Dental Journal. 2014 Marzo; 59(1).

20 Etapas del linfoma no Hodgkin [Internet]. Cancer.org. 2020 [citado 28 Julio 2020]. Available from: https://www.cancer.org/es/cancer/linfomano-hodgkin/deteccion-diagnostico-clasificacion-poretapas/clasificacion-por-etapas.html

21 Rosten A, Newton T. The impact of bulimia nervosa on oral health: A review of the literature. British Dental Journal. 2017 Octubre; 223.

22 Nakajima M, Kunawarote S, Prasansuttiporn T, Tagami. Bonding to caries-affected dentin. Japanese Dental Science Review. 2011 Agosto; 47(2).

23 Besek MJ. Un tratamiento fiable para la lesión dental cervical. De usuario. Coltene; 2013.

24 Mora Jiménez D. Consideraciones endodónticas en pacientes sometidos a quimioterapia y radioterapia. Odontología Vital. 2017 Julio - Diciembre;(27).

25 Vailati F, Belser UC. Full - Mouth Adhesive Rehabilitation of a Serverely Eroded Dentition: The three-Step technique. Part 2. The European Journal Of Esthetic Dentistry. 2008 Summer; 3(2).

26 Ministerio de Salud Pública del Ecuador. Protocolos Odontológicos. Protocolos Odontológicos. Quito: Ministerio de
Salúd Pública del Ecuador, Programa Nacional de Genética y Dirección Nacional de Normatización; 2014. Report No.: 978-9942-07-572-7.

27 Lévano Villanueva CJU. Manejo Del Paciente Oncológico Por El Odontólogo General. Revista Odontológica Basadrina. 2019 Enero; 1.

28 Rocha-Buelvas, Jojoa Pumalpa. Manejo odontológico de las complicaciones orales secundarias al tratamiento oncológico con quimioterapia y radioterapia. Rev.CES Odont. 2011; 24(2): p. 71-78. 
